\title{
Pulsus alternans in critical aortic stenosis
}

\author{
Stéphane Noble MD, Reda Ibrahim MD
}

A 65-year-old woman reported progressive shortness of breath over several months and paroxysmal dyspnea for two days without angina or syncope. On physical examination, carotid pulsations exhibited a slow upstroke, S2 was absent and a grade 3/6 aortic systolic murmur was noted. Evidence of congestive heart failure was noticed. Echocardiography showed critical aortic valvular stenosis with moderate left ventricular hypertrophy and severe left ventricular systolic dysfunction (left ventricular ejection fraction was 28\%). The coronary angiogram was normal. Via a transseptal approach, the mean transaortic gradient was $80 \mathrm{mmHg}$, with a calculated valve area of $0.35 \mathrm{~cm}^{2}$ (Fick cardiac output $3.4 \mathrm{~L} / \mathrm{min}$ or $1.7 \mathrm{~L} / \mathrm{min} / \mathrm{m}^{2}$ ). Pulsus alternans was noticed on the pressure tracings. The phenomenon is even more evident on the left ventricular curve (Figure 1).

The aortic valve was replaced with a bioprosthesis and the patient's recovery was uneventful. At the six-month follow-up examination, the patient was symptom free. Transthoracic echocardiography showed a normalized left ventricular ejection fraction without pulsus alternans during transaortic velocity measurement.

Pulsus alternans is attributed to an alteration of the stroke volume with every other cardiac cycle and it occurs most commonly in patients with severe left ventricular systolic dysfunction. The recovery of the ejection fraction was expected because of the high transvalvular gradient before surgery. Indeed, as long as the mean gradient is greater than $40 \mathrm{mmHg}$, there is virtually no low ejection fraction limit for surgical aortic valve replacement (1).

\section{REFERENCES}

1. Guidelines on the management of valvular heart disease. Eur Heart J 2007;28:230-68.

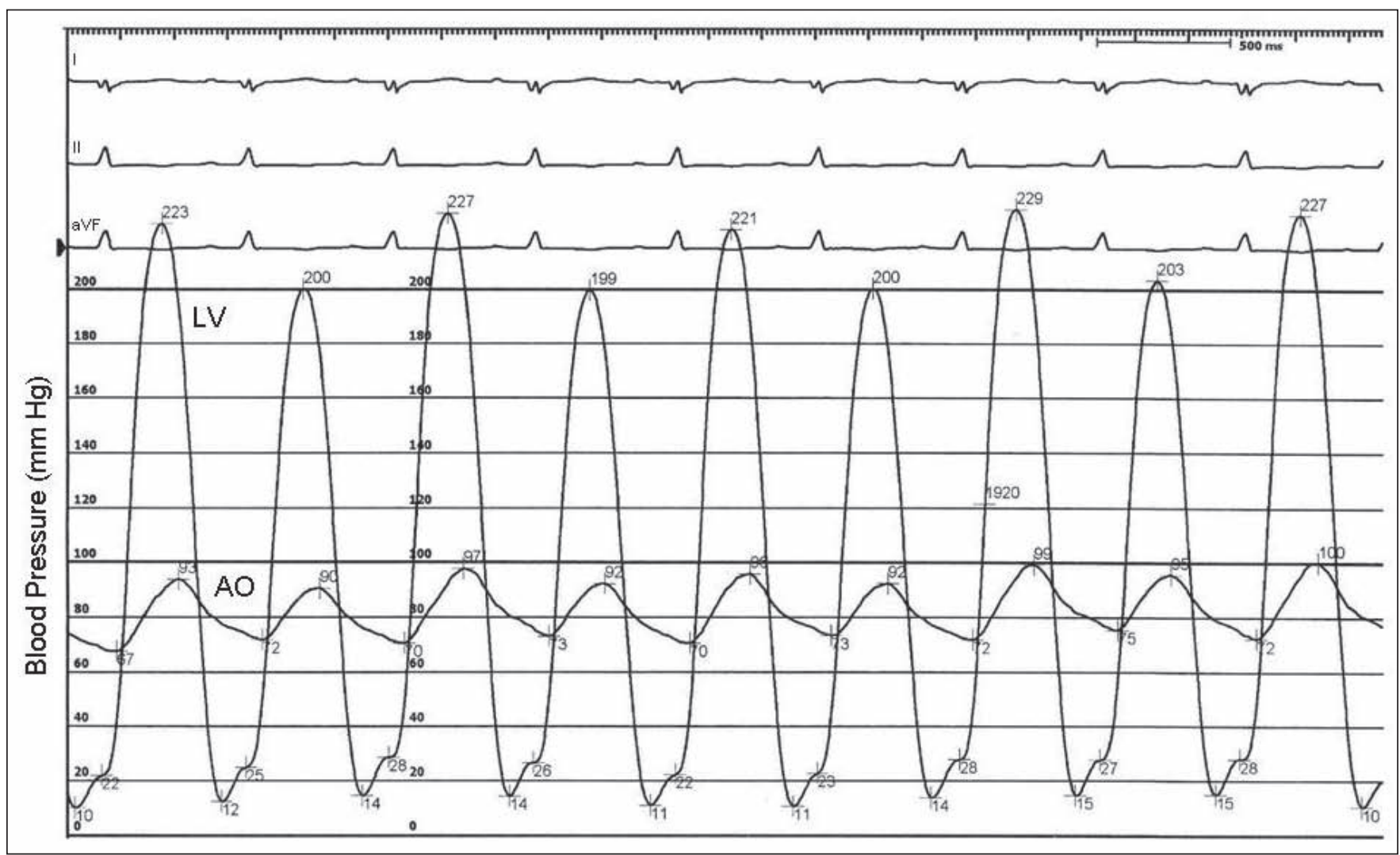

Figure 1) AO Aorta; LV Left ventricle

Department of Medicine, Montreal Heart Institute, Montreal, Quebec

Correspondence: Dr Reda Ibrahim, Department of Medicine, Montreal Heart Institute, 5000 East Belanger Street, Montreal, Quebec H1T 1C8.

Telephone 514-376-3330 ext 3800, fax 514-376-6299, e-mail reda.ibrahim@icm-mhi.org

Received for publication November 16, 2007. Accepted December 9, 2007 